\title{
Survey and Estimates of Commercially Viable Populations of the Sea Cucumber Actinopyga mauritiana (Echinodermata: Holothuroidea), on Tinian Island, Commonwealth of the Northern Mariana Islands ${ }^{1}$
}

\author{
Michael S. Trianni ${ }^{2}$ and Patrick G. Bryan ${ }^{3}$
}

\begin{abstract}
A survey was conducted in 1997 to assess commercially viable populations of the surf redfish, Actinopyga mauritiana, and establish a harvest quota for those populations on the island of Tinian. A simple random sampling approach was employed using circular plots as samples. Outer reef flat and reef slope habitats were sampled, producing a total of 333 samples over a 2-month period, with a preharvest population estimate of 71,034. A harvest quota of 17,893 surf redfish was established due to stock depletions on both Rota and Saipan, uncertainty of the density required to ensure successful reproduction of the species, and high degree of uncertainty in the population estimates. It was determined that a stratified sampling approach utilizing either simple proportional or optimal allocation would have resulted in more precise estimates, and these approaches are favored for any future survey work. Population estimates should be revised when more accurate estimates of $A$. mauritiana habitats become available.
\end{abstract}

Throughout the Indo-Pacific region sea cucumbers are harvested to produce the dried product bêche-de-mer or trepang. Harvest is primarily from tropical waters, although recently an expansion to temperate fisheries has occurred (Conand and Byrne 1993, Conand 2001). The major importers of bêche-de-mer are Hong Kong/China, Singapore, and Taiwan (Ferdouse 1999, Jacquemet and Conand 1999); the leading exporters have been Indonesia and the Philippines in the Pacific Ocean region, and Madagascar and Tanzania in the Indian Ocean region (Ferdouse 1999).

In recent years increased fishing effort on sea cucumber stocks in the Indo-Pacific has generated concern for the sustainability of sea cucumber fisheries. In addition, completions

${ }^{1}$ Manuscript accepted 30 May 2003

2 Commonwealth of the Northern Mariana Islands Division of Fish and Wildlife, P.O. Box 10007, Saipan, MP 96950 (E-mail: mstdfw@itecnmi.com).

${ }^{3}$ P.O. Box 731, Kea'au, Hawai'i 96749 (E-mail: pgbryan@hotmail.com).

Pacific Science (2004), vol. 58, no. 1:91-98

(C) 2004 by University of Hawai'i Press

All rights reserved of preharvest surveys and comprehensive management plans have been limited (Dalzell et al. 1996, Richmond 1996, Conand 1997, Jenkins and Mulliken 1999, Conand 2001).

In the Commonwealth of the Northern Mariana Islands (CNMI), commercial sea cucumber fisheries occurred on the islands of Rota (Trianni 2002a) and Saipan during 1995 and 1996, with limited harvesting on Tinian in 1996 and 1997 (Trianni 2002b). The target species was the surf redfish, Actinopyga mauritiana (Quoy \& Gaimard, 1833), with a circumstantial take of the black teatfish, $\mathrm{Ho}_{0}$ lotburia (Microthele) whitmaei (Bell, 1887), formerly Holotburia (Microthele) nobilis (Rowe \& Gates, 1995). Preharvest estimates of the targeted species were not obtained. The economic values of the surf redfish and the black teatfish have been listed as low and high, respectively (Conand 1990, SPC 1994).

In fall 1997, a commercial fishing company based in Saipan sought to harvest sea cucumbers around the island of Tinian $\left(14^{\circ} 57^{\prime} 15^{\prime \prime}\right.$ $\left.\mathrm{N}, 145^{\circ} 37^{\prime} 30^{\prime \prime} \mathrm{E}\right)$ due to declining catch rates on Saipan (Trianni 2002b). In response, the CNMI Division of Fish and Wildlife (DFW) conducted a survey to estimate the abundance of the target species, A. mauriti$a n a$, in areas of primary habitat so that a har- 
vest quota could be established based on the sampled sites. This paper presents the results of that survey.

\section{MATERIALS AND METHODS}

The usual habitat of $A$. mauritiana comprises the outer reef flat and adjacent reef slope, where strong surge and currents are present (Conand 1990, Kerr et al. 1993). This habitat harbors the commercially viable populations of the species (Zoutendyk 1989, Trianni $2002 b$ ). Potential harvest areas on Tinian were based on the Saipan fishery and included the outer reef flat through the reef slope to $6.1 \mathrm{~m}(20 \mathrm{ft})$, as well as a lagoon complex of fringing and patch reefs (Figure 1) (Eldredge and Randall 1980, Trianni 2002b). These habitat areas for $A$. mauritiana on Tinian were chosen from hydrographic charts (NOAA Chart 81067 and U.S. Naval Chart 6063).

Sampling was conducted using the technique of Amesbury and Kerr (1996). A 5.64-m polypropylene rope weighted at one end was used to create a circular plot with an area of $100 \mathrm{~m}^{2}$. Samples were taken randomly from the outer reef flat and the reef slope, to the $6.1-\mathrm{m}(20-\mathrm{ft})$ depth contour. The center of the circle plot was determined by randomly tossing a small weight tied with fluorescent surveyor tape into the primary habitat areas. All $A$. mauritiana and $H$. whitmaei occurring within a circular plot were enumerated. The outer reef flat sampling was accomplished on foot; the reef slope sampling was conducted by snorkeling. The outer reef flats were sampled during September 1997, with reef slopes sampled in October 1997. Outer reef flat and reef slope samples were pooled for abundance estimation at each site. The dot-grid method (Barrett and Philbrook 1970), and Geographic Information System (GIS) were used to estimate site area.

Simple random sampling (SRS) variance and population estimators following Cochran (1977) were used to obtain sea cucumber estimates from each site. Confidence intervals of the population estimates from SRS for each site were generated using the unbiased estimator of population variance:

$$
\begin{gathered}
\hat{V}(\hat{y})=N^{2} \hat{V}(\bar{y}) \\
\hat{y} \pm 2 \sqrt{\hat{V}(\hat{y})}
\end{gathered}
$$

where $N$ was the size of each area expressed as $100-\mathrm{m}^{2}$ circular plots, and $\hat{V}(\bar{y})$ equaled the unbiased estimate of the variance of the mean, $\left(s^{2} / n\right)^{*}(N-n / N)$. The overall estimate for the sites were obtained from addition of the individual site estimates.

The SRS analysis was compared with estimates generated if a stratified random sampling technique (StRS) using simple proportional allocation (SP) or optimal allocation (Opt) had been applied (Cochran 1977). For this comparison, each site sampled was considered a separate stratum, and for StRS Opt the cost per unit sampled was not considered to differ between strata. The allocation weights per stratum for StRS SP included only stratum size, whereas the allocation weights per stratum for StRS Opt included stratum size and stratum variance:

$$
W_{b}=\frac{N_{b} s_{b}^{2}}{\sum N_{b} s_{b}^{2}}
$$

The sample size per strata for StRS SP and Opt were determined from the total sample size and the strata allocation weights:

$$
n_{k}=W_{b}(n)
$$

\section{RESULTS}

A total of 333 samples was taken during the survey that counted a total of 1135 sea cucumbers. Only $9 \mathrm{H}$. whitmaei were counted, all from samples on the outer reef flat at Unai Dankulo.

Estimates of mean density, sample variance, habitat area, and population estimates for each site sampled are provided in Table 1. Rough sea conditions prevented sampling of the Unai Lamlam reef slope. Mean density values ranged from $0.3 / 100 \mathrm{~m}^{2}$ at Unai Babui to $4.9 / 100 \mathrm{~m}^{2}$ at Unai Dankulo for pooled outer reef flat/slope habitats, and the Lagoon site mean density was $5.8 / 100 \mathrm{~m}^{2}$. Mean density values for the outer reef flat ranged from $0.1 / 100 \mathrm{~m}^{2}$ to $5.7 / 100 \mathrm{~m}^{2}$, with an average of $4.1 / 100 \mathrm{~m}^{2}(n=244)$. Mean density 


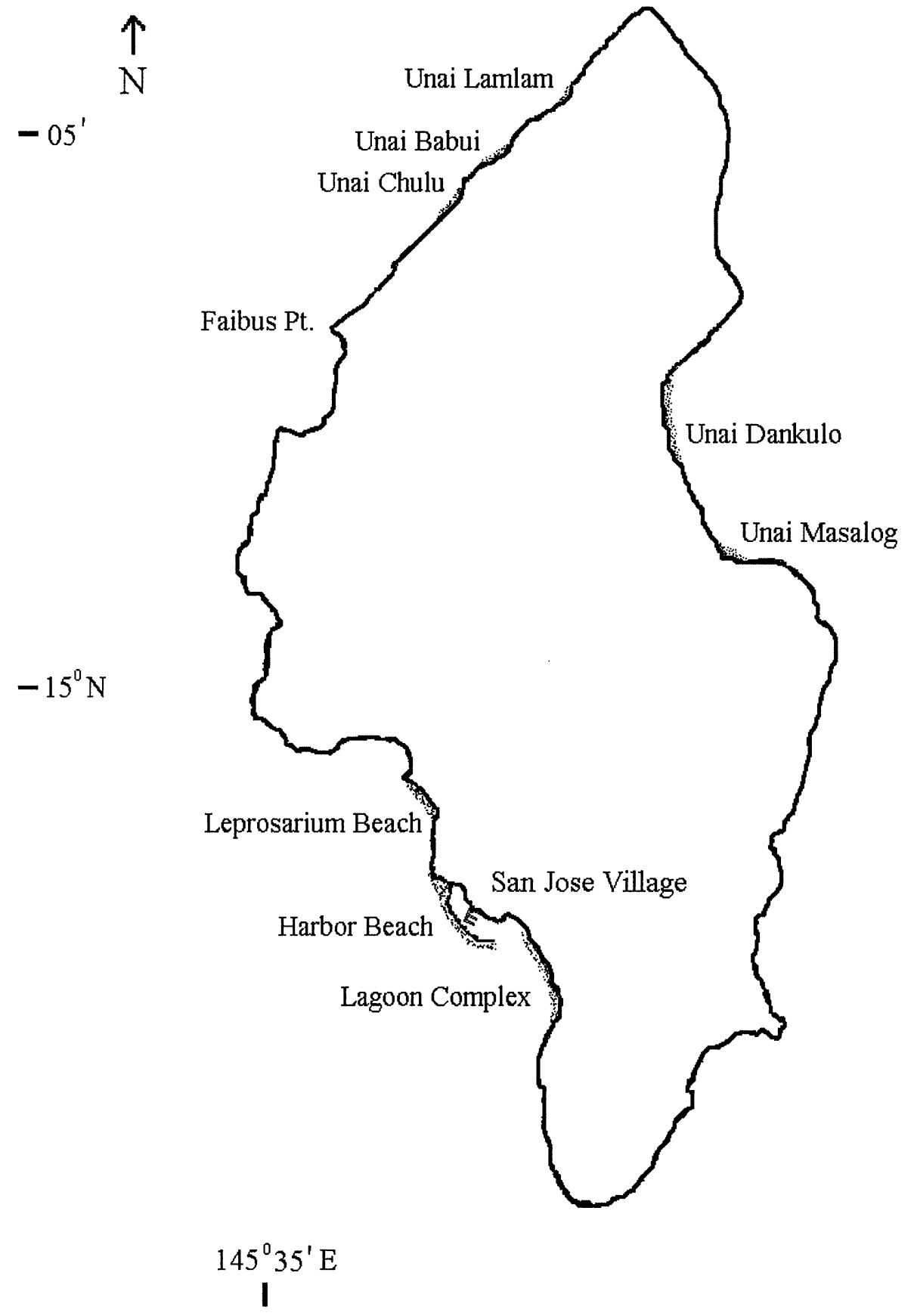

FIgURE 1. The island of Tinian showing sampled locations. 
TABLE 1

Mean Density Estimates, Sample Variance, Habitat Area, and Population Estimates for Sampled Sites on Tinian

\begin{tabular}{lccccccc}
\hline \hline & $\begin{array}{c}\text { Pample } \\
\text { Size }\end{array}$ & $\begin{array}{c}\text { Pooled } \\
\text { Density/ } \\
100 \mathrm{~m}^{2}\end{array}$ & $\begin{array}{c}\text { Reef Flat } \\
\text { Density/ } \\
100 \mathrm{~m}^{2}\end{array}$ & $\begin{array}{c}\text { Reef Slope } \\
\text { Density/ } \\
100 \mathrm{~m}^{2}\end{array}$ & $\begin{array}{c}\text { Sample } \\
\text { Variance } \\
\left(s^{2}\right)\end{array}$ & $\begin{array}{c}\text { Habitat } \\
\text { Area } \\
\left(\mathrm{km}^{2}\right)\end{array}$ & Population Estimate \\
\hline East side & & & & & & & \\
$\quad$ Unai Dankulo & 66 & 4.9 & 5.7 & 0.1 & 40.735 & 0.43 & $14,253<20,978<27,703$ \\
$\quad$ Unai Masalog & 31 & 3.1 & 4.5 & 0.1 & 27.129 & 0.02 & $268<610<952$ \\
West Side & & & & & & & \\
$\quad$ Lagoon Complex & 13 & 5.8 & & & 23.859 & 0.44 & $13,443<25,314<37,185$ \\
$\quad$ Harbor Beach & 116 & 3.9 & 4.8 & 0.8 & 22.939 & 0.48 & $14,381<18,554<22,728$ \\
$\quad$ Leprosarium Beach & 31 & 1.8 & 2.0 & 1.3 & 9.228 & 0.19 & $1351<3368<5386$ \\
$\quad$ Unai Chulu & 33 & 3.6 & 5.1 & 0.2 & 21.489 & 0.05 & $1050<1840<2629$ \\
$\quad$ Unai Babui & 39 & 0.3 & 0.1 & 0.8 & 0.654 & 0.06 & $37<180<322$ \\
$\quad$ Unai Lamlam & 4 & & 0.7 & & 0.917 & 0.02 & $-50<190<430$ \\
$\quad$ Totals & & & & & & 1.69 & $44,732<71,034<97,335$ \\
\hline
\end{tabular}

values for the reef slope ranged from $0.1 / 100$ $\mathrm{m}^{2}$ to $1.3 / 100 \mathrm{~m}^{2}$, with an average of $0.6 / 100$ $\mathrm{m}^{2}(n=76)$. The Unai Babui outer reef flat mean density was $0.1 / 100 \mathrm{~m}^{2}$, the lowest outer reef flat mean density sampled. It was also the only outer reef flat density that was lower than its corresponding reef slope density of $0.8 / 100 \mathrm{~m}^{2}$. Estimated habitat area ranged from $0.02 \mathrm{~km}^{2}$ at Unai Masalog and Unai Lamlam to $0.48 \mathrm{~km}^{2}$ at the Harbor Beach site.

Population estimates ranged from 180 at Unai Babui to 25,314 at the Lagoon site, with a total population estimate of 71,034 sea cucumbers. In comparing the sampled allocation with both StRS SP and StRS Opt (Table $2)$, the largest discrepancies were observed with the Lagoon site and Unai Babui, where the former was substantially undersampled and the latter substantially oversampled. Unai Dankulo was also notably undersampled. Stratification using SP or Opt provided similar allocation of sampling effort, with notable differences only in the allocations for the Unai Dankulo, Unai Babui, and Leprosarium sites. Using either StRS SP or Opt would have resulted in an equitable and greater degree of confidence in estimation of total population size (Table 2).

Relative sample precision was calculated using the following formula:

$$
p=\frac{s}{\sqrt{n_{r}} m}
$$

where $p=$ relative precision, $m=$ sample mean, $n_{r}=$ sample size, $s=$ sample standard deviation. This algorithm was used to determine the relative precision of the mean for each habitat type sampled, given the number of samples taken and estimates of the overall mean and variance per habitat type. Habitat types included the outer reef flat, reef slope, and lagoon complex, with relative precision estimates equaling $8.4,18.2$, and $23.8 \%$, respectively.

\section{DISCUSSION}

The estimated total of 71,034 was used in quota estimation for the sampled sites. In determining what percentage of the estimated total was made available for harvest, a number of points were considered.

The concept of reproductive success being correlated with population size is referred to as the "Allee effect," first described by Allee et al. (1949). The Allee effect postulates that a minimum threshold density may be required for successful reproduction in many plant and animal species. Most sea cucumbers, and all commercial species, are sedentary in nature and exhibit broadcast spawning (Preston 1993). The distance between males and females during spawning may be negatively correlated with reproductive success (Richmond et al. 1996), and sea cucumbers therefore may be highly susceptible to Allee 
TABLE 2

Comparison of Sample Size and Total Population Estimate between Simple Random Sampling (SRS) and Stratified Random Sampling (StRS) Utilizing Simple Proportional (SP) and Optimal Allocation (Opt)

\begin{tabular}{lccc}
\hline \hline Location & SRS & StRS SP & StRS Opt \\
\hline East Side & & & \\
$\quad$ Unai Dankulo & 66 & 85 & 113 \\
Unai Masalog & 31 & 4 & 4 \\
West Side & & & 88 \\
$\quad$ Lagoon Complex & 13 & 97 & 93 \\
Harbor Beach & 116 & 37 & 23 \\
Leprosarium Beach & 31 & 10 & 2 \\
Unai Chulu & 33 & 11 & 1 \\
Unai Babui & 39 & 5 & $62,214<71,034<79,854$ \\
Unai Lamlam & 4 & $61,870<71,034<80,198$ & \\
$\quad$ Estimates & $44,732<71,034<97,335$ & & \\
\hline
\end{tabular}

dynamics. It is unclear whether juvenile recruitment in sea cucumbers is linked to adult density, availability of food, or habitat characteristics (Ebert 1983, Richmond 1996). No strategy exists that specifies what density of a particular sea cucumber species is sufficient to ensure reproductive and recruitment success.

Catch-effort analysis from the commercial fishery on Saipan estimated the initial population of $A$. mauritiana/H. whitmaei within harvested areas to be about 165,273 , of which approximately $99 \%$ were $A$. mauritiana, at a mean density of about $3.2 / 100 \mathrm{~m}^{2}$. The mean densities found on the Tinian outer reef flats ranged from 0.1 to $5.7 / 100 \mathrm{~m}^{2}$, and the mean densities on the reef slopes ranged from 0.1 to $1.3 / 100 \mathrm{~m}^{2}$. The low densities from the Unai Babui and Unai Lamlam outer reef flat sites were considered to be due to the homogeneous habitat structure, flat pavement with few holes and crevasses, which appeared to be a suboptimal habitat for $A$. mauritiana. A postharvest transect survey on Saipan found outer reef flat densities and reef slope densities to range from 0.0 to $1.2 / 100 \mathrm{~m}^{2}$ and from 0.1 to $1.0 / 100 \mathrm{~m}^{2}$, respectively (Trianni $2002 b$ ). A survey of commercially viable sea cucumbers in Saipan Lagoon by Tsuda (1997) in October 1996 found A. mauritiana density on a patch reef to be $4.0 / 100 \mathrm{~m}^{2}$. Recorded estimates of $A$. mauritiana in other Pacific reef areas have ranged from 0.1 to $8.7 / 100 \mathrm{~m}^{2}$ (Preston 1993, Dalzell et al. 1996). Survey results from Chuuk Island in 1988 suggested that populations there had not recovered from the high exploitation levels that occurred during the Japanese Mandate years from the 1920s to1940s (Smith 1947, Richmond 1996). The long-term effects of the high exploitation rates on $A$. mauritiana populations on Rota and Saipan, in terms of mean density, have not been evaluated.

Island geography and oceanographic conditions such as current direction are factors influencing density, dispersal, and recruitment of planktotrophic sea cucumber larvae (Preston 1993). The high exploitation rates of the same species on Rota and Saipan, south and north of Tinian, respectively, and the planktotrophic nature of sea cucumber larvae, coupled with a prevailing northeastsouthwest current, amplified concern for populations on Tinian. Nine of the 10 islands north of Saipan belong to a geologically younger island arc composed of substantial volcano-clastic sediments, with coral reef development limited to narrow fringing reef zones (Eldredge 1982). The sea cucumber resources in those islands have never been assessed, although the limited reef development is suggestive of low population numbers for a species such as the surf redfish that thrives in surge zones of outer reef flats and barrier reefs. Observations from fringing reef habitat on Saipan, Farallon de Medinilla, and Pagan (located about $50 \mathrm{nmi}$ and $200 \mathrm{nmi}$ north of Saipan, respectively) support this premise (M.S.T., pers. obs.). 
The uncertainty in the population estimate was underscored by the wide estimation intervals derived from SRS in comparison with StRS SP and Opt, and the large discrepancies in sample effort between SRS and StRS SP and Opt (Table 2). The low sample size and low precision of the Lagoon Complex site reflected a high degree of uncertainty in the estimate from that site. Also, the low sample size from Unai Lamlam resulted in confidence limits that ranged from -50 to 430 (Table 1). The use of GIS software enhanced area estimation of sampled sites, but the NOAA and U.S. Navy nautical charts used were too imprecise to delineate the actual specific habitat of the surf redfish, prompting additional uncertainty in population estimation.

Unauthorized harvests occurred on Tinian in 1996 and 1997. In November 1996, 1751 A. mauritiana were harvested at Unai Dankulo. In May 1997 Tinian Conservation Officers returned an unauthorized harvest of about $500 \mathrm{~A}$. mauritiana to the reef slope at Unai Chulu (mortality unknown). An additional 2090 A. mauritiana were harvested from Tinian in May 1997 from an unknown location.

These considerations resulted in the adoption of a precautionary approach and no harvest was recommended. If harvest were to occur a limit of no more than $40 \%$ of the lower estimated number of sea cucumbers in the areas surveyed, approximately 17,893 , would be imposed and no $H$. whitmaei could be taken. As a result of the overexploitation of the surf redfish on Rota and Saipan, in 1998 a 10-yr moratorium was placed on the harvest of sea cucumbers in the Commonwealth of the Northern Mariana Islands.

Sladek Nowlis and Roberts (1999) modeled the potential of marine reserves permanently closed to fishing to enhance long-term fishery yields. Key assumptions of their model were that adults did not cross reserve boundaries and larvae dispersed beyond reserve boundaries. In general they concluded that species with low intrinsic growth rates would require reserves even with low fishing mortality. Given the sedentary nature, planktotrophic larval period, and slow growth rate of A. mauritiana (Preston 1993) the results from Sladek Nowlis and Roberts (1999) seem applicable to this and probably other species of sea cucumber. A recent study of $H$. whitmaei density in fished and unfished areas on the Great Barrier Reef suggested that an effective management tool for the conservation of holothurian stocks would be the protection of whole reefs from fishing, because the division of reefs into fishing and nonfishing zones did not appear adequate (Uthicke and Benzie 2001). This tends to corroborate the results from Sladek Nowlis and Roberts (1999). In areas such as the Mariana Islands that consist of comparatively smaller reefs, future management strategies would therefore necessitate the designation of entire islands as nonfishing zones. Richmond (1996) proposed that management of sea cucumbers be addressed at the regional level of Micronesia.

The purpose of the Tinian survey was to obtain a population estimate for $A$. mauritiana toward the goal of generating a rational harvest quota in the sampled sites. The sampling strategy would have benefited if the number of samples necessary to achieve a predetermined level of precision had been established before sampling. The circle plot sampling method proved to be practical, although obtaining preliminary estimates of the mean and variance for the method was not possible due to logistical considerations and time constraints. It is anticipated that publishing of such values here will prove useful to other resource managers.

Stratification by site using simple proportional or optimal allocation would have provided an efficient usage of resources in determining more accurate population estimates and are the preferred approaches for future surveys, although caution is advised in the use of simple proportional allocation in estimating exploited populations of $A$. mauritiana. Further stratification of habitat by reef flat and reef slope would also be beneficial, because large differences in density were apparent between habitat types. Finally, it is recommended that estimates be revised when more accurate estimates of $A$. mauritiana habitats are obtained. 


\section{ACKNOWLEDGMENTS}

We gratefully acknowledge Jacinto Taman, Raymond Roberto, Greg Camacho, Fred Falig, and Alfred Castro for their field assistance. Doug Mauro of CNMI Coastal Resources Management Office provided GISbased area estimates of the sites.

\section{Literature Cited}

Allee, W. C., A. E. Emerson, O. Park, T. Park, and K. P. Schmidt. 1949. Principles of animal ecology. W. B. Saunders, Philadelphia, Pennsylvania.

Amesbury, S. S., and A. M. Kerr. 1996. Data collection methods for beche-de-mer resource management in Micronesia. Pages 53-59 in R. Richmond, ed. Suggestions for the Management of Sea Cucumber Resources in Micronesia, Results of the Workshop, A regional management plan for a sustainable sea cucumber fishery for Micronesia. Univ. Guam Lab. Tech. Rep. 101.

Barrett, J. P., and J. S. Philbrook. 1970. Dot grid area estimates: Precision by repeated trials. J. For. 68:149-151.

Cochran, W. G. 1977. Sampling techniques. 3rd ed. John Wiley \& Sons, New York.

Conand, C. 1990. The fishery resources of Pacific island countries. Part 2: Holothurians. F.A.O. Fish. Tech. Pap. 272 (2). 1997. Are holothurian fisheries for export sustainable? Proc. Int. Congr. Reefs, Panama, 2:2021-2026.

. 2001. Overview of sea cucumbers fisheries over the last decade-What possibilities for a durable management? Pages 339-344 in M. Barker, ed. Echinoderms 2000. Swets \& Zeitlinger, Lisse, the Netherlands.

Conand, C., and M. Byrne. 1993. A review of recent developments in the world sea cucumber fisheries. Mar. Fish. Rev. 55:1-13.

Dalzell, P., T. J. H. Adams, and N. V. C. Polunin. 1996. Coastal fisheries in the $\mathrm{Pa}$ cific Islands. Oceanogr. Mar. Biol. Annu. Rev. 34:395-531.

Ebert, T. A. 1983. Recruitment in echinoderms. Pages 169-203 in M. Jangoux and
J. M. Lawrence, eds. Echinoderm studies.

Vol. 1. A. A. Balkema, Rotterdam.

Eldredge, L. G. 1982. Summary of environmental and fishing information on Guam and the Northern Mariana Islands: Historical background, description of the islands, and review of the climate, oceanography, and submarine topography. NOAA Tech. Memo. NMFS-SWFC-40.

Eldredge, L. G., and R. H. Randall. 1980. Atlas of the reefs and beaches of Saipan, Tinian and Rota. University of Guam Marine Laboratory.

Ferdouse, F. 1999. Bêche-de-mer markets and utilization. South Pac. Comm. Bechede-Mer Inf. Bull. 11:3-9.

Jacquemet, S., and C. Conand. 1999. The bêche-de-mer trade in 1995/1996 and an assessment of exchanges between the main world markets. South Pac. Comm. Bechede-Mer Inf. Bull. 12:11-14.

Jenkins, M., and T. A. Mulliken. 1999. Evolution of exploitation in the Galapagos Islands: Ecuador's sea cucumber trade. TRAFFIC (Wildlife Trade Monitoring Network) Bull. 17 (3): 107-118.

Kerr, A. M., E. M. Stoffel, and R. L. Yoon. 1993. Abundance distribution of holothuroids (Echinodermata: Holothuroidea) on a windward and leeward fringing coral reef, Guam, Mariana Islands. Bull. Mar. Sci. 52 (2): 780-791.

Preston, G. L. 1993. Bêche-de-mer. Pages 371-407 in A. Wright and L. Hill, eds. Nearshore marine resources of the South Pacific. Institute of Pacific Studies, Forum Fisheries Agency, Honiara, and International Centre for Ocean Development, Halifax.

Richmond, R. 1996. Introduction and overview. Pages 2-6 in R. Richmond, ed. Suggestions for the management of sea cucumber resources in Micronesia, Results of the workshop, A regional management plan for a sustainable sea cucumber fishery for Micronesia. Univ. Guam Lab. Tech. Rep. 101.

Richmond, R., D. Hopper, and P. Martinez. 1996. The biology and ecology of sea cucumbers. Pages 7-31 in R. Richmond, ed. Suggestions for the management of sea 
cucumber resources in Micronesia, Results of the workshop, A regional management plan for a sustainable sea cucumber fishery for Micronesia. Univ. Guam Lab. Tech. Rep. 101.

Rowe, F. W. E., and J. Gates. 1995. Echinodermata. In A. Wells, ed. Zoological catalogue of Australia. Vol. 33. CSIRO, Melbourne.

Sladek Nowlis, J., and C. Roberts. 1999. Fisheries benefits and optimal design of marine reserves. Fish. Bull. 97:604-616.

Smith, R. O. 1947. Summary of the fisheries of the former Japanese Mandated Islands. U.S. Fish Wildl. Serv. Fish. Leafl. 273.

SPC. 1994. Sea cucumbers and bêche-de-mer of the tropical Pacific: A handbook for fishers. South Pacific Commission Handbook no. 18 .

Trianni, M. S. 2002a. Summary of data collected from the sea cucumber fishery on Rota, Commonwealth of the Northern
Mariana Islands. Beche-de-Mer Info. Bull. 16:5-11. $2002 b$. Evaluation of the resource following the sea cucumber fishery of Saipan, Northern Mariana Islands. Proc. 9th Int. Coral Reef Symp., Bali, Indonesia (in press).

Tsuda, R. T. 1997. Survey of commercially valued sea cucumbers in the Saipan $\mathrm{La}-$ goon, CNMI. Beche-de-Mer Info. Bull. 9:15-17.

Uthicke, S., and J. A. H. Benzie. 2001. Effect of bêche-de-mer fishing on densities and size structure of Holothuria nobilis (Echinodermata: Holothuroidea) populations on the Great Barrier Reef. Coral Reefs 19:271-276.

Zoutendyk, D. 1989. Trial processing and marketing of surf redfish (Actinopyga mauritiana) bêche-de-mer on Rarotonga, and its export potential in the Cook Islands. Ministry of Marine Resources Report, Cook Islands. 